\title{
On the generalizability of Pāninin's pratyāhāra-technique to other languages
}

\author{
Wiebke Petersen and Silke Hamann \\ Heinrich-Heine-Universität Düsseldorf \\ wiebke.petersen@phil.uni-duesseldorf.de \\ hamann@phil.uni-duesseldorf.de
}

\begin{abstract}
Pānini defines the sound classes involved in grammatical rules by pratyāhāras, i.e., a two-letter code based on the order of the sounds in the Śivasutras. In the present paper we demonstrate that Pānini's pratyāhāra method is generalizable to the description of the phonological systems of other languages by applying it to the sound classes and phonological alternations of German. Furthermore, we compare Pāninini's pratyāhāra technique with the technique of describing phonological classes by phonological features, which is more common in Western phonology. It turns out that pratyāhāras perform better than features for the description of our sample of German phonological processes if one considers the quality criterion for class-description devices proposed by Kornai (1993) which is based on the ratio of describable to actual classes.
\end{abstract}

Keywords: Panini, Sivasutras, phonological features, sound classes, formal concept analysis

\section{Introduction}

The Astā dhyāy $\bar{\imath}$ - Pānini's circa 2500 years old grammar of Sanskrit - starts with the Śivasūtras, a list of the sounds of Sanskrit. Throughout his grammar, Pānini uses the so-called pratyāhāras - a two-letter code based on the order of the sounds in the Sivasūtras - to define the sound classes involved in grammatical rules. Since Pānini's time, the Śivasūtras have been studied intensively with focus on the following questions: Is the order of the sounds in the Sivasutras determined by the rules in the Asț $\bar{a} d h y \bar{a} y \vec{\imath}$ ? Why does one sound (the glottal [h]) occur twice in the list? Are the Śivasūtras minimal? And how did Pānini develop the Śivasūtras?

In the present article we make a first attempt to describe the phonological processes of another language with the help of a Śivasūtra-like list and pratyāhāras. For this purpose we chose German, another Indo-European language with a phonological system that differs considerably from Sanskrit. We propose a list of all German sounds in the style of the Sivasūtras that allows us to refer to the sound classes relevant for the description of German phonological processes 
in the form of pratyāhāras. This Sivasūtra-like list of sounds will be called pratyāhāra sūtras in the following. Our aim is to test what the formalization of pratyāhāra sūtras for another language entails, and how far such a description differs from the phonologically more common description of sound classes with phonological features.

The remainder of the paper is structured as follows. In section 2, we introduce two ways of referring to sound classes and phonological processes: the language-independent description of processes with phonological features and Pānini's approach with Śivasūtras and pratyāhāras that was especially designed for Sanskrit. Section 3 gives a short overview of the German sound system and the phonological processes that are the basis for our analysis of German. In the central section 4 we propose pratyāhāra sūtras for German. Finally, in section 5 we conclude with a brief discussion of our results.

\section{Describing sound classes and phonological processes}

Phonology is concerned with the sound system of a language and the alternations that these sounds undergo. In phonological theory, alternations between sounds are called phonological processes. In German, for instance, plural forms of nouns often involve a number of alternations compared to the singular forms, see the example in (1).

$$
\text { Hand [hant] 'hand' - Hände [hendə] 'hands' }
$$

In (1), the vowel [a] in the singular alternates with the vowel $[\varepsilon]$ in the plural, and the consonant $[\mathrm{t}]$ in the singular alternates with the consonant $[\mathrm{d}]$ in the plural. Generative phonologists describe such processes by assuming that only one of the alternants is the form that native speakers or listeners have stored in their mind, while the other alternating form is derived from it. The sound representations stored in the mind are usually called underlying representations and are denoted in slashes, and the sounds that the speakers actually produce or the listeners hear are termed surface representations and are denoted in square brackets. For the singular-plural alternation in (1), it is usually assumed that the /d/ is the underlying representation, and the $[\mathrm{t}]$ is derived from it by a process that is called final devoicing (see section 3.2.1 below).

Phonological processes can be described in terms of phonological rules. These rules are typically of the form "the underlying sound / A / is realized as the surface sound $[\mathrm{B}]$ if it is preceded by sound C and/or followed by sound D". This can be formalized as

$$
/ \mathrm{A} / \rightarrow[\mathrm{B}] / \mathrm{C}-\mathrm{D}
$$

The variables A, B, C and D in (2) can stand for single sounds, but also for classes of sounds. Whole classes of sounds can thus undergo a phonological process, be the result of a phonological process or pose the context of such a process. Sound classes can be described in several ways. In the following two subsections, we 
shortly present the commonly employed phonological description with features (2.1) and the description by pratyāhāras introduced by Panini for Sanskrit (2.2).

\subsection{Featural descriptions}

Instead of listing whole classes of sounds in phonological processes, phonological descriptions usually employ phonological features. The key assumption of this description technique is that every sound in a language can be described sufficiently by a set of binary features, making it distinct from all other sounds in the same language (cf. Jakobson et al., 1952). Phonological features have acoustic, articulatory or auditory definitions. For instance, the feature [+high] is defined as an articulation with a high tongue body. Accordingly, the feature [-high] also refers to the dimension of tongue position; it is defined as an articulation with a non-high tongue body. Sounds that share a feature and therefore a phonetic trait are called a natural class. The Spanish vowels [i u], for instance, are the only vowels in Spanish with the feature [+high] and therefore form a natural class in Spanish.

Unnatural classes of sounds are those that do not share a phonetic trait, and they usually do not occur as undergoer, result or context of a phonological process. A well-known example of an unnatural class is the context of the socalled ruki-rule in Sanskrit (Whitney, 1889, 61f.). According to this process, the segments $[\mathrm{r}],[\mathrm{u}],[\mathrm{k}]$ and $[\mathrm{i}]$ cause retroflexion of the dental $[\mathrm{s}]$. The four segments forming the context of this rule form no natural class but rather an arbitrary set of sounds, because they involve two types of vowels (the back vowel $[\mathrm{u}]$ and the front vowel $[\mathrm{i}]$ ), and two types of consonants (a retroflex $[\mathrm{r}]$ and a velar $[\mathrm{k}]$ ), which cannot be referred to by one or a few phonological features. To describe this class, all feature specifications of all four segments have to be given. A situation like this, where the context of a rule cannot be referred to by a single or a few features, is called a disjunction in the phonological literature (e.g. Kenstowicz, 1994, 216). The disjunct context of the ruki-rule probably diachronically emerged from the merger of several processes (see the discussion in Hamann, 2003, chapter 4.3.4).

'Binary phonological features' are a relatively modern concept; the first complete set of features has been proposed by Jakobson et al. (1952). However, the traditional Śikṣās- and Prātiśākhyas-literature, which even predates Pāṇini, already classifies sounds by phonetic criteria that can be interpreted as phonological features (cf. the elaborated varga system of the sparśas as described in Deshpande, 1995; Staal, 1995). In his grammar, Pāninini uses the varga system in addition to his pratyāhāra technique.

\subsection{Pānini's Śivasūtras}

Pānini's grammar of Sanskrit, the Asțtādhyāy $\bar{\imath}$, is preceded by the 14 sūtras given in Figure 1, which are called Sivasūtras. Each single sūtra consists of a sequence of sounds which ends in a consonant. This last consonant of each sūtra is used meta-linguistically as a marker to indicate the end of a sūtra. In order 


\section{अइउण् ऋल्क् एओड् ऐंच् हयवरट् लण् अमङणनम् झभन् घढधष् जबगडदश खफछठथचटतव् कपय् शषसर् हल्}

a.i·un r.ḷ e·on ai·auc hayavarat lạ ñamanananam jhabhañ ghaḍhadhaṣ jabagaḍadaś khaphachaṭhathacaṭatav kapay śaṣasar hal

aiu $M_{1} \quad \operatorname{rl} M_{2}$ eo $M_{3}$ ai au $M_{4}$ hyvr $M_{5} \quad M_{6}$ ñm $\operatorname{nnn} M_{7}$ jh bh $M_{8}$ gh dh dh $\dot{M}_{9}$ jbgdd $M_{10}$ kh phehththcṭt $M_{11}$ kp $M_{12}$ śs ș $M_{13}$ h $M_{14}$

Fig. 1. Pāninini's Śivasūtras for Sanskrit (I: Devanāgarī script; II: Latin transcription; III: Analysis - the syllable-building vowels are left out and the metalinguistically used consonants are replaced by neutral markers $M_{i}$ )

to emphasize the technical nature of the end consonants, they are replaced by neutral marker elements $M_{i}$ in Figure 1(III). Together the 14 Śivasūtras define a linear order on the sounds of Sanskrit. The order is such that more or less each class of sounds on which a phonological rule of Pānini's grammar operates forms an interval which ends immediately before a marker element. ${ }^{1}$ As a result, Pānini could use a two letter code consisting of a sound and a marker called pratyāhāra in order to designate the sound classes in his grammar. A pratyāhāra denotes the continuous sequence of sounds in the interval between the sound and the marker (including the first sound, but non of the markers). E.g., the pair $i M_{2}$ in Figure 1 denotes the class [i, $\mathrm{u}, \mathrm{r}, \mathrm{l}]$.

Concerning the question of how Pānini developed the Śivasūtras, it is generally agreed upon that the order of the sounds in the Sivasutras is primarily determined by the structural behavior of the sounds in the grammar rules and that the arrangement of the sounds is chosen such that brevity is maximized (cf. Staal, 1962; Misra, 1966; Cardona, 1969; Kiparsky, 1991). Petersen (2004) proves that Pānini's Śivasūtras are an optimal solution for the following task: Given the set of all phonological classes which are encoded as pratyāhāras in the Asta $\bar{a} d h y \bar{a} y \bar{\imath}$, construct a list which is interrupted by markers such that each class can be denoted as a pratyāhāra. Choose the list where the fewest sounds are repeated and minimize its length. It follows from the proof that the duplication of the sound $[\mathrm{h}]$ in the Śivasūtras is not superfluous and that the number of markers and thereby the number of Śivasūtras cannot be reduced. In Petersen (2008, 2009 ) it could be shown that there are nearly 12000000 alternative sound lists interrupted by markers which allow the formation of the required pratyāhāras and which are of the same length as the Śivasūtras.

\footnotetext{
${ }^{1}$ As mentioned before, Pāṇini uses different description techniques in parallel. Hence,
} he states not every phonological rule in terms of pratyāhāras. 


\section{The phonemes and phonological processes of German}

In order to describe the phonological processes of German with the technique of Pāṇini's pratyāhāras, we first have to establish the sound system of German and its phonological alternations. This is not a trivial task. While for Sanskrit it is generally accepted that Pạnini's grammar describes the phonological system of the language, no such undisputable description exists for German. Establishing the sound system of German involves decisions on whether certain sounds are considered to be mentally stored (underlyingly represented), or whether they are considered surface alternants that can be derived from another underlying form via a process. Underlying forms are usually meaning-distinguishing units with relatively unrestricted occurrences, and called phonemes, while those forms that are derived and have only a restricted context are called allophones. If a sound in a language is classified as an allophone, the phonological description of the language has to include a process to describe its derivation from an underlying phoneme. The velar nasal [y], for instance, is considered by some phonologists (e.g. Vennemann, 1970; Wiese, 1996) to be an allophone of the alveolar nasal phoneme/n/ in German because it only occurs after a vowel and before a syllable break, in the so-called coda position. Such decisions on the phoneme status of a sound are often made purely on theoretical grounds: Chomsky and Halle (1968), e.g., postulated that the number of phonemes should be as small as possible while the number of processes is unrestricted. The following description of German is based on Wiese (1996) and Hall (2000) and the theoretical assumptions therein.

\subsection{The sounds of German}

The consonants and vowels of German forming the basis of our analysis are given in Figure 2 and 3, respectively (based on Hall, 2000, pp. 31, 62, 68).

In Figure 2, two consonants are given in brackets, namely the glottal plosive [?] and the velar fricative [x]. These sounds are bracketed in Figure 2 because their occurrence is predictable from the context and can therefore be derived with a process: The glottal stop occurs before syllable-initial stressed vowels, and

\begin{tabular}{|c|c|c|c|c|c|c|c|c|}
\hline \multirow[b]{2}{*}{ plosive } & bilabic & $\begin{array}{l}\text { abio } \\
\text { lenta }\end{array}$ & veol & alveola & & vela & & otta \\
\hline & $\mathrm{p} \mathrm{b}$ & & $\mathrm{t} d$ & & & $\mathrm{~kg}$ & & (?) \\
\hline nasal & $\mathrm{m}$ & & $\mathrm{n}$ & & & $\mathrm{y}$ & & \\
\hline fricative & & $\mathrm{f} \mathrm{v}$ & $\mathrm{S} \mathrm{Z}$ & $\int 3$ & ç & $(\mathrm{x})$ & B & $\mathrm{h}$ \\
\hline affricate & & pf & ts & $\mathrm{t} \int \mathrm{d}_{3}$ & & & & \\
\hline approximant & & & & & $\mathrm{j}$ & & & \\
\hline lateral & & & 1 & & & & & \\
\hline
\end{tabular}

Fig. 2. Consonants of German 


$$
\begin{aligned}
& \text { i: (i) y: (y) } \\
& \text { u: (u) } \\
& \text { I Y } \\
& \text { e: (e) } \varnothing:(\varnothing) \\
& \varepsilon: \varepsilon \propto \quad \text { } \propto \\
& \text { o: (o) } \\
& \text { a: a }
\end{aligned}
$$

Fig. 3. Vowel triangle with vowels of German

the velar fricative after low and back vowels, as described with the phonological processes in 3.2.3 and 3.2.5 below. All other sounds in Figure 2 can be considered phonemes of German.

The vowels of German are given in Figure 3. Again, the sounds given in brackets are considered to be allophones of underlying phonemes. These are the low vowel $[\bullet]$, which is the realization of the German / $\mathrm{s} /$ in coda position and therefore predictable, and the short tense vowels $[i, y, u, e, \varnothing, o]$. These short tense vowels are allophones of the long tense /i:, y:, u:, e:, $\varnothing:$, o:/. The latter only occur in stressed position, while the former only occur in unstressed position, see the phonological process of vowel shortening in 3.2.4.

In addition to the vowels in Figure 3, German also has three diphthongs; these are vowels that change their quality during the articulation. The diphthongs of German are [गI, aI, av $]$.

\subsection{Phonological processes of German}

The present description is restricted to processes that involve classes of sounds. These classes can be the undergoer, the result or the context of a phonological process. Processes where only single segments are involved are excluded because they are of no relevance for a description with Śivasūtras or phonological features. Such a process is for instance the vocalisation of the German / $\mathrm{s} /$ to [e] in coda position (see e.g. Wiese, 1996, pp. 252ff. for a detailed description). The following six processes meet this criterion and therefore seem to be relevant for our descriptions.

3.2.1 Final devoicing German, like many other languages, has a process of final devoicing that turns a class of voiced consonants into voiceless ones if they occur in word-final position (see e.g. Wiese, 1996, pp. 199ff.). In the example in (1), the plural Hände [hendə] 'hands' is realized as [hant] with a final [t] in the singular.

The whole list of sounds that undergo German final devoicing are given in the formalization in (3).

$$
/ \mathrm{b}, \mathrm{d}, \mathrm{g}, \mathrm{v}, \mathrm{z}, \mathrm{3} / \rightarrow[\mathrm{p}, \mathrm{t}, \mathrm{k}, \mathrm{f}, \mathrm{s}, \mathrm{f}] / \text { — word boundary }
$$


The group of sounds undergoing this process are traditionally described as $o b$ struents, a term that refers to all plosives, fricatives, and affricates in a language. As we can see in Figure 3, German has more obstruent phonemes than the ones listed in rule (3). The input to the rule lacks all affricates and the fricatives [ç, $\mathrm{s}, \mathrm{h}]$. While the voiceless phonemes [pf, ts, ç, h] cannot undergo final devoicing because they have no voiced counterpart, the voiced $\left[\mathrm{d}_{3}\right]$ and $[\mathrm{s}]$ are phonemes that do not occur in coda position, and therefore do not meet the requirements of the process, either.

In featural accounts of phonological processes, the voiced obstruents of German are referred to with the phonological features [+voiced, -sonorant], and the voiceless obstruents with [-voiced, -sonorant]. A rule with features would thus look as follows:

$(3)^{f} \quad$ [+voiced, -sonorant $] \rightarrow[$-voiced, -sonorant $] /$ _ word boundary

This rule is hyper-inclusive in the sense that it theoretically affects all obstruents. Empirically, however, it is harmless as only the plosives and part of the fricatives occur in the relevant context and thus undergo the rule.

3.2.2 Regressive nasal assimilation The nasal alveolar $/ \mathrm{n} /$ is often assimilated to its following context in German. The word /ankunft/ 'arrival', for instance, can be realized as [ạkwnft], and /arnfaret/ 'gateway' as [armfaret]. This so-called regressive assimilation of nasals has to be formalized as two processes, velar and labial assimilation, distinguishing the two types of outcome:

$$
\begin{aligned}
& \left./ \mathrm{n} / \rightarrow[\mathrm{y}] / \mathrm{Lk}_{\mathrm{g}} \mathrm{g}\right] \\
& \text { velar nasal assimilation }
\end{aligned}
$$

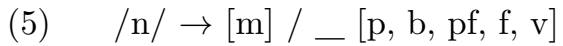

The two contexts of nasal assimilation can be referred to with the features [+velar, -sonorant, - continuant] for [k, g], and the features [+labial, -sonorant] for $[\mathrm{p}, \mathrm{b}, \mathrm{pf}, \mathrm{f}, \mathrm{v}]$.

3.2.3 Glottal stop epenthesis Vowel-initial words in German are always realized with a preceding glottal stop [?], e.g. /aI/ 'egg' is realized as [?aI]. The distribution of the glottal stop is formalized in the following epenthesis rule, a rule that inserts segments:

(6) $\quad \emptyset \rightarrow[?] /$ word boundary vowel

The regular and predictable occurrence of the glottal stop is the reason why it is not considered a phoneme of German by many phonologists. The class of vowels forming the context of glottal stop epenthesis can be referred to with the phonological feature [-consonantal].

3.2.4 Vowel shortening The German vowels [i:, y:, e:, $\varnothing_{\text {: }}, \mathrm{u}$, o: $]$, which are referred to as long and tense vowels, only occur in stressed position. Their short 
counterparts $[\mathrm{i}, \mathrm{y}, \mathrm{e}, \varnothing, \mathrm{u}, \mathrm{o}]$, on the other hand, only appear in unstressed position, and are restricted to loanwords, e.g. the first vowel in [monaeçi: 'monarchy'. This complementary distribution led most phonologists to tread the short tense vowels as allophones of the long ones and to describe their distribution with a process as it is formalized in (7).

$$
\text { /i:, y: e: },: \text { u: o: } / \rightarrow[\mathrm{i}, \mathrm{y}, \mathrm{e}, \varnothing, \mathrm{u}, \mathrm{o}] / \text { _unstressed }
$$

The long, tense vowels are usually referred to with the features $[+$ long, +tense, -consonantal], and their short counterparts with [-long, +tense, - consonantal].

3.2.5 Palatal fricative assimilation The palatal fricative / ç/ is articulated with a more backed tongue position, i.e. as the velar fricative $[\mathrm{x}]$, after the vowels [a: a, u:, , o: , ว, av ]. This process is described in (8).

$$
/ \mathrm{c} / \rightarrow[\mathrm{x}] /[\mathrm{a}: \mathrm{a}, \mathrm{u}, \mathrm{v}, \mathrm{o:}, \text {, av }]
$$

The context vowels for palatal fricative assimilation can be described with the phonological features [-consonantal, +low] for [a: a], and [-consonantal, +back] for $\left[u_{i}, v, o:\right.$, , av]. This class is an example for a disjunct phonological context, where the sounds forming the context cannot be united under one feature description.

3.2.6 Umlaut In German, we can observe a process of vowel change that has lost its phonological context. This process, called umlaut, changes the vowels /u:,

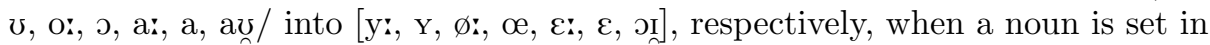
the plural. The example [hant] - [hendə] 'hand (sg. - pl.)' in (1) illustrated this. Umlaut also occurs for diminutive forms of nouns and the comparative forms of many adjectives, see e.g. Wiese (1996) (1996: 182f.). A formalization is given in (9), though the context is not specified because the process is morphologically conditioned.

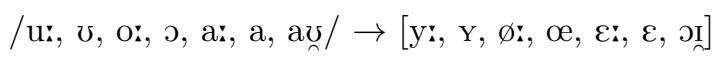

Such a process is familiar to Sanskrit scholars from the Sanskrit ablaut grades termed guna and vṛddhi.

For a description with phonological features, this process has to be divided into three subprocesses. The sounds [u:, , o: , o] are [-consonant, - low, +back] and change to $[\mathrm{y}:, \mathrm{y}, \varnothing \mathrm{z}, \propto]$ with the feature specification $[-$ consonant, - low, + front]. The sound class [a: a] with the specification [-consonant, +low] changes to $[\varepsilon: \varepsilon]$ with the specification $[-$ consonant, -low, - high, +front, -tense]. And lastly, the single segment [avn] changes to [ə⿳亠丷厂 ].

The six processes described in this section involve ten classes of sounds, namely the input and output of final devoicing, the context of labial and velar nasal assimilation, the context of glottal stop epenthesis, the input and output of 
vowel shortening, the context of palatal fricative assimilation, and the input and output of the umlaut process. For a featural description of these processes, a total of 16 features has to be used. ${ }^{2}$ In the following section we will see how an account with pratyāhāras for the same processes looks.

\section{Pratyāhāra sūtras of German}

In section 3, we defined the collection of phonological processes and thereby implicitly the set of 10 phonological classes which we intend to represent as pratyāhāras. Hence, our task is to develop a list of the German sound segments interrupted by markers in the style of the Sivasūtras which allows the formation of a pratyāhāra for each phonological class of the collection. A simple but undesirable solution to the problem would be to line up the phonological classes in one single list and to put a marker behind each class. In such a list, the number of occurrences of a phonological segment would be equal to the number of phonological classes to which the phonological segment belongs. Since Pānini duplicates in his Śivasūtras only one segment, namely [h], it is obvious that the Śivasūtras are constructed more economically: Pānini aims at the minimization of the number of duplicated segments and the reduction of markers (Kiparsky, 1991).

In Petersen $(2008,2009)$ the general problem of generating economical pratyāhāra sūtras for given sets of sets has been tackled by applying methods from Formal Concept Analysis (FCA) (Ganter and Wille, 1999). In what follows we will apply those former results in order to construct adequate, economical pratyāhāra sūtras for German. A small example helps to clarify the required terminology of FCA:

In Figure 4 (left) an example set of four classes, namely $\{a, b\},\{b, c\},\{c, d\}$, and $\{a, b, c\}$, is given in form of a formal context. A cross in the table indicates that an element (top row) belongs to a class (first column). All four classes can be denoted as pratyāhāras of the list of pratyāhāra sūtras

$$
d c M_{1} b M_{2} a M_{3} \text { (pratyāhāras: } b M_{3}, c M_{2}, d M_{1}, c M_{3} \text { ) }
$$

Note that no element in the pratyāhāra sūtras occurs twice. The concept lattice of the formal context is the set of all intersections (ordered by the inverted subset relation) which can be generated from the classes (plus the set of all elements). For our example, the set of all intersections is

$$
\{\{\},\{c\},\{b\},\{a, b\},\{b, c\},\{c, d\},\{a, b, c\},\{a, b, c, d\}\} .
$$

Figure 4 (right) shows a Hasse diagram of the concept lattice, i.e., a Hasse diagram of the set of the eight intersection sets ordered by the inverted subset relation. In the diagram the nodes (circles) correspond to the intersection sets

\footnotetext{
${ }^{2}$ In order to make our analysis independent of the theoretical assumption that features are binary, we treat features like $[+$ high $]$ and $[-$ high $]$ as two distinct privative features.
} 

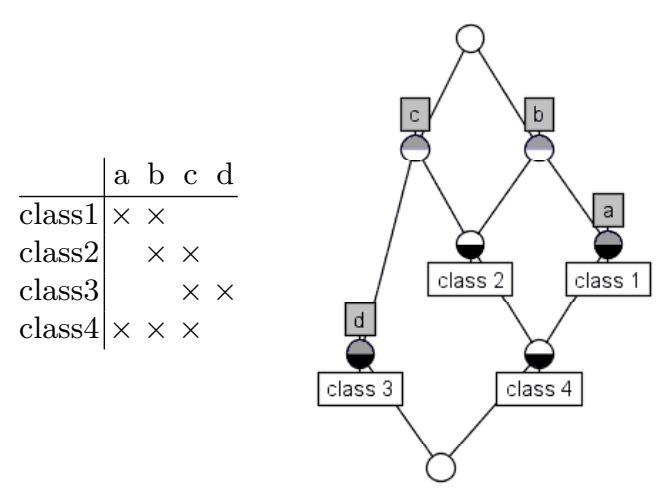

Fig. 4. Example formal context (left) with corresponding concept lattice (right)

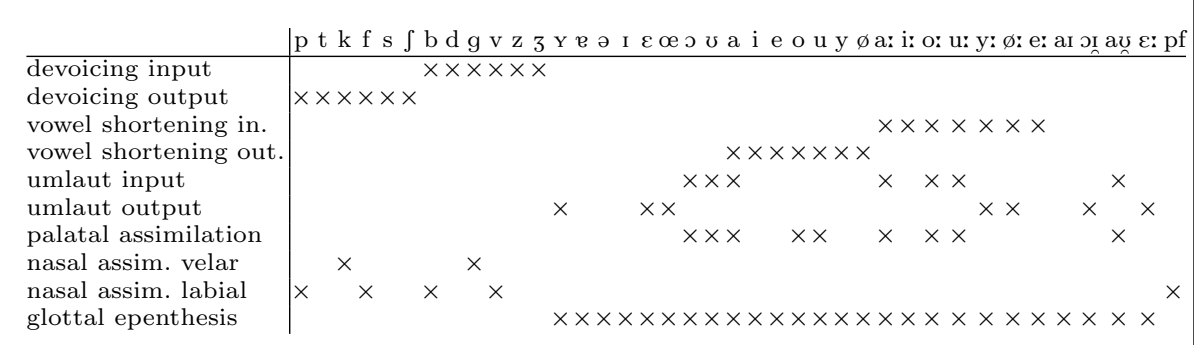

Fig. 5. Formal context for the phonological classes of German (due to space limits, the segments $\left[\mathrm{d}_{3}, \mathrm{t} \int \mathrm{ts}, \mathrm{s}, \mathrm{l}, \mathrm{y}, \mathrm{n}, \mathrm{m}, \mathrm{j}, \mathrm{P}, \mathrm{h}, \mathrm{c}, \mathrm{x}\right]$ which belong to no class are left out)

and an edge between two nodes indicates that the set associated with the upper node is a subset of the one associated with the lower node and that no other intersection set is a superset of the set associated with the upper and a subset of the set associated with the lower node. The diagram is labeled as follows: each segment is written above the node corresponding to the smallest set to which it belongs, e.g., $c$ labels the node for the set $\{c\}, b$ the node for the set $\{b\}$, and $a$ the one for $\{a, b\}$. The labeled Hasse diagram can be read as an inheritance hierarchy: each node corresponds to the set of segments by which the node or one of its supernodes is labeled. E.g., the node for 'class 4' corresponds to the set $\{a, b, c\}$, the bottom node corresponds to $\{a, b, c, d\}$, and the top node to the empty set.

The formal context for our collection of phonological classes for German is given in Figure 5. Petersen (2004) proves that it is impossible to order the phonological segments in pratyāhāra sūtras without a single duplication if the 


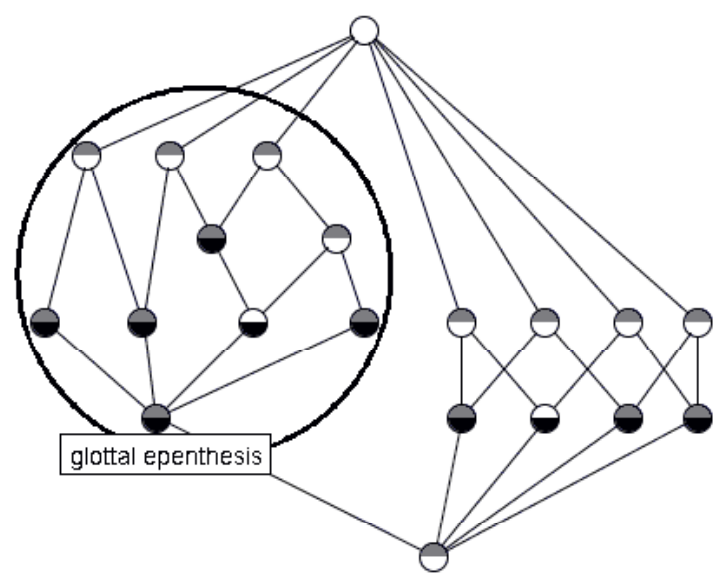

Fig. 6. Concept lattice for the phonological classes of German (the big circle indicates the planar part constituted by the vowel segments)

corresponding concept lattice is not planar, i.e., if it is impossible to draw a Hasse diagram without intersecting edges. A Hasse diagram of the concept lattice of the formal context for our phonological classes of German is given in Figure 6. In order to improve readability, most of the labels are left out. One part of the diagram, namely the one corresponding to the subsets of the phonological class 'glottal epenthesis' (i.e. the vowels), stands out, as it is plane. The question is whether it is possible to give a plane drawing, i.e. a drawing without intersecting edges, of the remaining part of the diagram. By Figure 7 we will argue that such a drawing is impossible.

Figure 7 (top) shows a Hasse diagram with intersecting edges of the concept lattice of the formal context constituted by the four classes 'devoicing output', 'devoicing input', 'nasal assimilation labial', and 'nasal assimilation velar'. According to Kuratowski (1930) and Platt (1976), a lattice has no plane diagram if it is possible to gain the graph $\otimes$ (i.e. the complete graph $K^{5}$ ) from the graph of the diagram enlarged by an additional edge connecting the lowest and the top most node by removing some of the edges and contracting others. It is obvious that the graph in Figure 7 (top) can be constructed from the one in Figure 6 by leaving out some of the edges. The sequence of drawings at the bottom of Figure 7 starts with the graph from the top of the figure enlarged by an additional edge connecting the top and the bottom node. Each remaining graph is gained from its left neighbor by contracting the emphasized edge (thick grey edge). As the final graph is isomorphic to the graph $₫$, the sequence proves that it is impossible to draw a diagram of the concept lattice in Figure 6 without intersecting edges. Hence, the concept lattice of the formal context of our collection of phonological classes is not planar. It follows that it is impossible to construct 


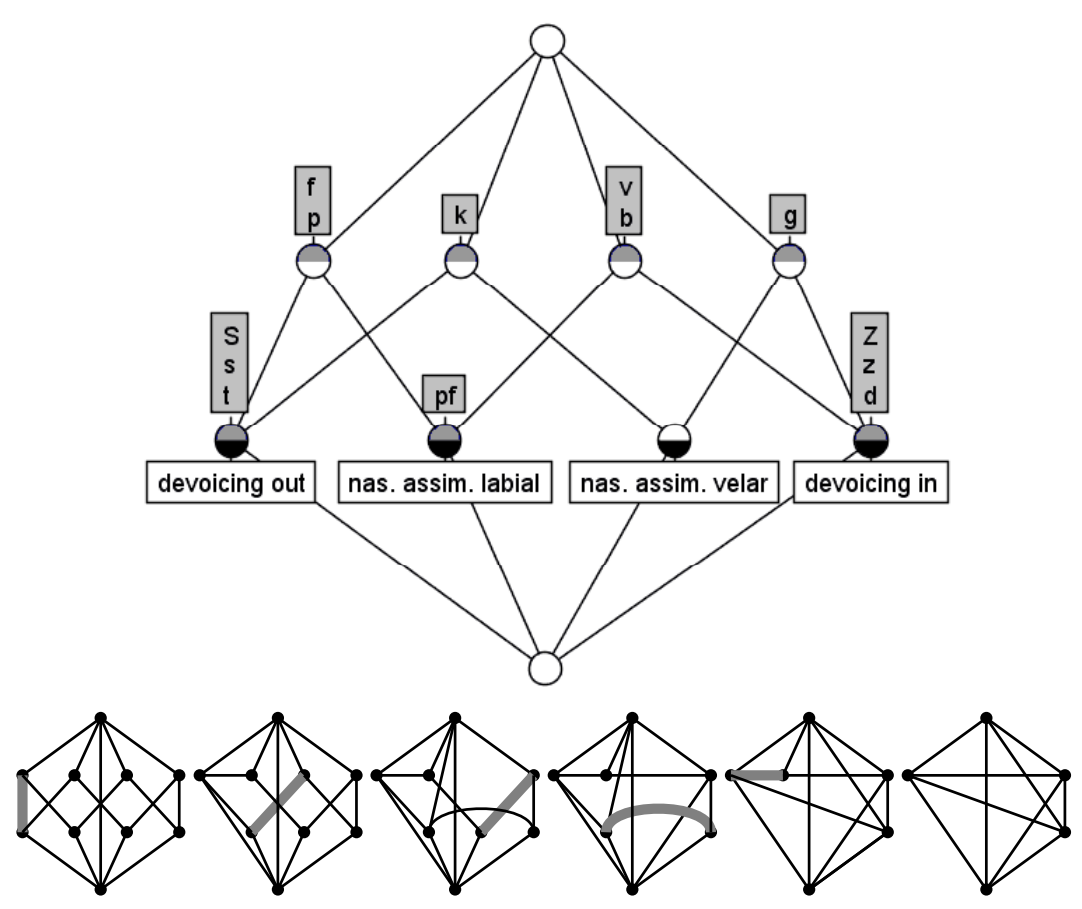

Fig. 7. Non-planar concept lattice for a selection of the phonological classes of German (key: $\mathrm{S} \mapsto[\mathrm{S}], \mathrm{Z} \mapsto[3]$ )

pratyāhāra sūtras for the formal context in which each sound segment occurs only once. Hence, analogously to the Śivasūtras for Sanskrit we are forced to repeat at least one sound segment for our pratyāhāra sūtras for German.

Thus, the next step towards pratyāhāra sūtras for German is the identification of sound segments which are good candidates for duplication. Hence, we are interested in identifying those segments for which we can add a copy to our formal context in Figure 5 and distribute the crosses in the table between the two copies in such a way that the corresponding concept lattice gets planar. The aim thereby is to copy as few sound segments as possible. Note that the nodes of the four minimal nonempty sets $(\{\mathrm{f}, \mathrm{p}\},\{\mathrm{k}\},\{\mathrm{v}, \mathrm{b}\},\{g\})$ in Figure 7 do not differ structurally with respect to their position in the concept lattice. Thus, it is better to duplicate one of the segments $[\mathrm{g}]$ or $[\mathrm{k}]$ than one of the remaining four segments, as duplicating for example the segment [f] would force one to duplicate the segment $[\mathrm{p}]$ too, since these two segments are not distinguishable with respect to the chosen phonological classes. In what follows we will concentrate on the duplication of the segment $[\mathrm{g}]$; the duplication of $[\mathrm{k}]$ would give analogous results. 


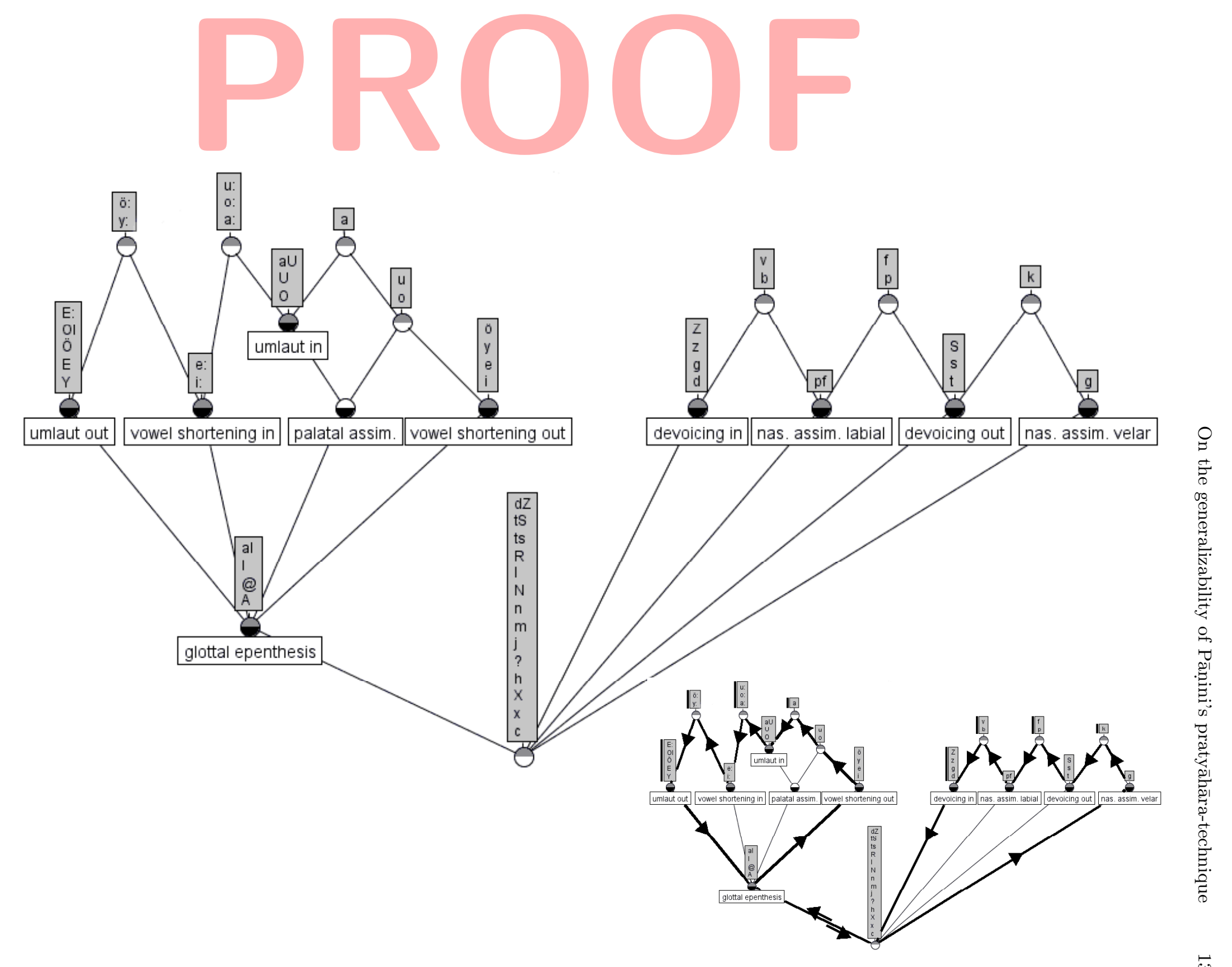

Fig. 8. Concept lattice without top node for the phonological classes of German (key: c $\mapsto[c], S \mapsto\left[\int\right], ? \mapsto[?], \mathrm{Z} \mapsto[3], \mathrm{N} \mapsto[\mathrm{y}], \mathrm{R} \mapsto$ $[\mathrm{r}], \mathrm{Y} \mapsto[\mathrm{y}], \mathrm{A} \mapsto[\mathrm{e}], @ \mapsto[\ni], \mathrm{I} \mapsto[\mathrm{I}], \mathrm{E} \mapsto[\varepsilon], \ddot{\mathrm{O}} \mapsto[\propto], \mathrm{O} \mapsto[\mathrm{\jmath}], \mathrm{U} \mapsto[\mho], \ddot{\mathrm{o}} \mapsto[\varnothing], \ddot{\mathrm{o}}: \mapsto[\varnothing \mathrm{c}], \mathrm{aI} \mapsto[\mathrm{ar}], \mathrm{OI} \mapsto[\mathrm{\jmath I}], \mathrm{aU} \mapsto[\mathrm{av}], \mathrm{E}: \mapsto$ $[\varepsilon \mathrm{z}], \mathrm{tS} \mapsto\left[\mathrm{t} \int\right)$ 
If in the formal context in Figure 5 the segment $[\mathrm{g}]$ is replaced by two copies one classified as 'devoicing input' and the other one as 'nasal assimilation velar' a plane Hasse diagram of the resulting concept lattice can be drawn (cf. Figure 8). In the diagram in Figure 8, the top node of the concept lattice, which corresponds to the empty set, is left out. The boundary graph of the diagram is called the $S$-graph of the formal context. In Petersen (2008) it has been proven that the $\mathrm{S}$-graph of a formal context is unique up to isomorphism if the formal context can be encoded as pratyāhāra sütras without duplicated elements. Furthermore, the main theorem on S-sortability (Petersen, 2009, 2008) states that a formal context can be encoded as pratyāhāra sūtras without duplicated elements if and only if its concept lattice is planar and its S-graph contains all nodes labeled by elements. The following procedure quoted from Petersen (2009) allows one to read off pratyāhāra sūtras with a minimal number of markers from the S-graph of a formal context.

Procedure for the construction of S-alphabets (here: pratyāhāra sūtras) with minimal marker sets:

1. Start with the empty sequence and choose a walk through the S-graph that:

- starts and ends at the lowest node,

- reaches every node of the S-graph,

- passes each edge not more often than necessary,

- is oriented such that while moving downwards as few labeled nodes with exactly one upper neighbor as possible are passed.

2. While walking through the S-graph modify the sequence as follows:

- While moving upwards along an edge do not modify the sequence.

- While moving downwards along an edge add a new marker to the sequence unless its last element is already a marker.

- If a labeled node is reached, add the labels in arbitrary order to the sequence, except for those labels which have already been added in an earlier step.

Applied to our context of phonological classes of German, an optimal walk through the S-graph is depicted in the lower right of Figure 8. It starts at the bottom node and runs first through the consonantal part and then through the vowel part of the S-graph. The walk through the vowel part of the S-graph is oriented counter-clockwise since this guarantees that while moving downwards as few labeled nodes with exactly one upper neighbor as possible are passed. The orientation of the walk through the consonantal part can be arbitrarily chosen. By traversing the depicted walk the following eight pratyāhāra sütras for German can be read off:

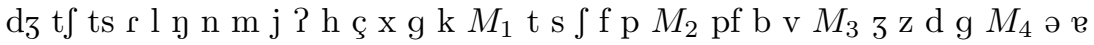
I ar $\varnothing$ y e i u o a $M_{5}$ v ว av a: o: u: $M_{6}$ i: e: y: $\varnothing: M_{7} \varepsilon:$ ग $\propto$ y $\varepsilon M_{8}$

The first sūtra results from collecting all unclassified sounds at the bottom node and then walking upwards to the nodes labeled ' $g$ ' and 'k'. Since the walk goes 
downwards after reaching the node labeled ' $\mathrm{k}$ ', a first marker $M_{1}$ has to be added to the sequence. The other sutras are constructed analogously. One sound segment, namely [g] occurs twice in the list of pratyāhāra sūtras, namely in the first and the fourth sütra. It is obvious that the phonological classes of German do not uniquely determine a list of pratyāhāra sūtras. ${ }^{3}$ As mentioned, the pratyāha ara sūtras would differ if another walk through the S-graph would be chosen which could for example go first through the vowel part or traverse the consonantal part clockwise. Additionally, all sound segments by which a single node is labeled can be added to the pratyāhāra sūtras in any desired order. Finally, instead of duplicating the sound segment [g], the sound segment $[\mathrm{k}]$ could have been duplicated, resulting in different pratyāhāra sūtras .

The pratyāhāra sūtras given above yield the following pratyāhāras for the 10 phonological classes from our formal context in Figure 5:

$g M_{1}$ : Input to velar nasal assimilation

$\mathrm{f}_{3}$ : Input to labial nasal assimilation

$\mathrm{b} M_{4}$ : Input to final devoicing

$\mathrm{k} M_{2}$ : Output to final devoicing

$\mathrm{u} M_{6}$ : Context of palatal fricative assimilation

a $M_{6}$ : Input to umlaut

y: $M_{8}:$ Output to umlaut

a: $M_{7}:$ Input to vowel shortening

$\varnothing M_{5}$ : Output to vowel shortening

ә $M_{8}$ : Context of glottal epenthesis

In the remainder of this section we will demonstrate how the pratyāhāras for German can be employed for the description of the phonological rules discussed in section 3.2. The problem we are faced with is that phonological rules treat phonological classes not always as plain sets. In a phonological rule only the left and right contexts are unordered sets; the input and the output class has to be linearly ordered. The reason for this is that if a phonological rule is viewed as a rewriting rule then it has to be ensured that each segment of the input class has to be rewritten by its corresponding segment of the output class; e.g., the rule for final devoicing has to ensure that /d/ is rewritten as [t] and not as [k]. Pāṇini's Śivasūtras fulfill this constraint, his pratyāhāras are considered to be linearly ordered sets. But our formal model of the pratyāhāra technique so far does not take internally ordered sound classes into account. By our definitions pratyāhāras denote unordered sets. Our approach only guarantees that the resulting pratyāhāra sūtras offer the possibility to form for each phonological class a pratyāhāra which denotes the unordered set of the elements of the class. However, for the concrete example of phonological classes for German we were able to arrange the sounds in our pratyāhāra sūtras such that the order of the sounds in

\footnotetext{
${ }^{3}$ As mentioned in section 2.2, there are nearly 12000000 pratyāhāra sūtras of the same length for Sanskrit from which Pāninini has chosen one sample (i.e., the Śivasūtras).
} 
the input classes corresponds to the reversed order of the sounds in the output classes. Take for example the rule of final devoicing (rule (3) in section 3.2):

(3)' $\quad \mathrm{b} M_{4} \rightarrow \mathrm{k} M_{2} /$ _ word boundary

final devoicing

Here, the pratyāhāra $\mathrm{b} M_{4}$ denotes the class $[\mathrm{b} \vee 3 \mathrm{z} \mathrm{d} \mathrm{g}]$ and $\mathrm{k} M_{2}$ the class [k $\mathrm{t}$ $\left.\mathrm{s} \int \mathrm{f} \mathrm{p}\right]$. Hence, $\mathrm{k} M_{2}$ denotes the devoiced counterparts of the elements of $\mathrm{b} M_{4}$ in reversed order. The remaining rules of section 3.2 can be stated in terms of pratyāhāras as follows:

(4) $)^{\prime} \quad / \mathrm{n} / \rightarrow[\mathrm{n}] / \mathrm{g}_{1}$

(5),$\quad / \mathrm{n} / \rightarrow[\mathrm{m}] / \mathrm{f}_{3}$

(6)' \{\}$\rightarrow[?] /$ word boundary ${ }_{\partial} M_{8}$

(7)' a: $M_{7} \rightarrow \varnothing M_{5} /$ _ unstressed

(8)' $/ \mathrm{c} / \rightarrow[\mathrm{x}] / \mathrm{u} M_{6}$

(9) $)^{\prime} \quad$ a $M_{6} \rightarrow \mathrm{y}: M_{8}$ velar nasal assimilation

labial nasal assimilation

glottal stop epenthesis

vowel shortening

palatal fricative assimilation

umlaut

Hence, all phonological processes of German described in section 3.2 can be rewritten with pratyāhāras of our proposed pratyāhāra sūtras.

\section{Discussion}

By describing the sound classes and phonological alternations of German with Pānini's pratyāhāra technique we have demonstrated that the pratyāhāra method is generalizable to the description of the phonological systems of other languages. Pāninini's aim while constructing his Sivasūtras was to allow the formation of a pratyāhāra for every phonologically motivated class, i.e. for every class that is needed in the description of the phonological processes of Sanskrit. He did not construct pratyāhāras for all phonetically-based classes of sounds in a fashion that modern phonological features do. In the present article, we applied both methods, namely the description with pratyāhāra sütras based solely on phonological processes and the description with features based on phonetic criteria, to a sample of phonological processes of German. ${ }^{4}$ Our phonological system of German consisted of 52 sound segments. This yields a total of $2^{52}=4503599627370496$ potential sound classes; just 10 of those classes are actually required for the description of our sample of phonological processes of German.

Any method for describing phonological classes which is not simply listing their elements overgenerates in the sense that it allows the formulation of classes which are needed in no phonological rule. The ratio of describable to actual

\footnotetext{
${ }^{4}$ Petersen (2004) combined the pratyāhāra account and the featural account in an analysis of the vowel system of German and a constructed language, by transferring the featural specifications for the vowels into pratyāhāras. It turned out that this demanded the duplication of disproportionately many sounds.
} 


\begin{tabular}{|c|c|}
\hline $\mathrm{t} \int \mathrm{ts} \rho \operatorname{lgnmj} P \mathrm{~h} c \mathrm{x}$ & $15 \times$ \\
\hline $\mathrm{t} \mathrm{s} \int \mathrm{f} \mathrm{p} M_{2}$ & $5 \times 7$ \\
\hline $\mathrm{pf} \mathrm{b} \vee M_{3}$ & $3 \times 6$ \\
\hline $3 \mathrm{z} \mathrm{d} \mathrm{g} M_{4}$ & $4 \times 5$ \\
\hline ә e I al $\varnothing$ y e i u o a $M_{5}$ & $11 \times 4$ \\
\hline ひ ว av a: o: u: $M_{6}$ & $6 \times 3$ \\
\hline i: e: y: $\varnothing: M_{7}$ & $4 \times 2$ \\
\hline$\varepsilon:$ ગ & $5 \times 1$ \\
\hline
\end{tabular}

Fig. 9. The pratyāhāra sūtras for German in tabular form

classes constitutes a quality criterion for class-description devices (Kornai, 1993). Considering our example of German phonology, we get the following results: The pratyāhāras for the 10 required classes are given in section 4, but how many pratyāhāras can be formed with our pratyāhāra sūtras? Figure 9 lists the pratyāhāara sütras for German and calculates for each single sūtra the number of pratyāhāras which can be build with its sound elements. For instance, each of the 5 sound elements of the second sutra can be combined with any of the succeeding 7 markers $M_{2} \ldots M_{8}$ in order to form a pratyāhāra. Altogether 268 pratyāhāras can be formed. ${ }^{5}$ Although at first glance the ratio of describable to actual classes seems low for the pratyāhāra method, this method still performs better than the description with phonological features: In section 3 we used a total of 16 features to describe the phonological processes under consideration. But 16 features yield a total of $2^{16}=65536$ classes which can be described by feature sets, thus far more than by pratyāhāras. Even if one drops the requirement that features should have acoustic, articulatory or auditory definitions and allows for unnatural features, a featural description of the 10 phonological classes cannot perform better than our pratyāhāra description. As none of our 10 classes can be described in terms of an intersection of some of the other classes, every featural description which is able to distinguish those 10 classes has to make use of at least 10 different features. A minimal featural description of the 10 classes would be to use the class identifiers (e.g., 'devoicing input', 'devoicing output') as features. Such a description would be minimal since none of the features would be reducible to other features. 10 features still yield a total of $2^{10}=1024$ classes which can be described by feature sets; this is nearly four times more than by the pratyāhāras we employed.

One objection against our approach could be that we are only considering seven phonological processes while Pānini is describing many more processes in the Astādhyāy . The main reason for this is that German exhibits far less Sandhi phenomena than Sanskrit. Furthermore, there is no standard description

\footnotetext{
${ }^{5}$ Usually one would exclude pratyāhāras which are formed by the final sound segment and the marker of a pratyāhāra sūtra and which thus only denote single sound segments. Therefore, only 260 pratyāhāras of our pratyāhāra sūtras are well-formed.
} 
of the complete phonological system of German comparable to the Astāadhyāy $\overline{\text {. }}$ In this paper we refrained from testing how hyper-inclusive processes could yield a more economic description of German. The main reason for this is that our mathematical approach to the induction of the pratyāhāra sūtras is not yet able to automatically identify cases of harmless hyper-inclusivity. This is left for future research.

It is important to note that Pānini pursues a mixed strategy for the description of phonological classes: they are denoted by pratyāhāras (e.g., sūtra 6.1.77), they are referred to by the older phonetical varga-classification (e.g., sūtra 3.1.8) or their elements are simply listed (e.g., sūtra 1.1.24). In contrast to Pāninini we restricted ourselves to the pratyāhāra-method. 


\section{Bibliography}

Cardona, G. (1969). Studies in Indian grammarians I: The method of description reflected in the Śiva-Sūtras. Transactions of the American Philosophical Society, 59(1):3-48.

Chomsky, N. and Halle, M. (1968). The Sound Pattern of English. Harper and Row, New York.

Deshpande, M. M. (1995). Ancient Indian phonetics. In Koerner, E. F. K. and Asher, R. E., editors, Concise History of the Language Sciences: From the Sumerians to the Cognitivists, pages 72-77. Elsevier, Oxford, New York, Tokyo.

Ganter, B. and Wille, R. (1999). Formal Concept Analysis. Mathematical Foundations. Berlin.

Hall, T. A. (2000). Phonologie: Eine Einführung. Walter de Gruyter, Berlin.

Hamann, S. (2003). The Phonetics and Phonology of Retroflexes. PhD thesis, Utrecht Institute of Linguistics.

Jakobson, R., Fant, G., and Halle, M. (1952). Preliminaries to Speech Analysis: The Distinctive Features and their Correlates. MIT Press, Cambridge (Mass.).

Kenstowicz, M. (1994). Phonology in Generative Grammar. Blackwell, Cambridge.

Kiparsky, P. (1991). Economy and the construction of the Śivasūtras. In Deshpande, M. M. and Bhate, S., editors, Pāninian Studies. Ann Arbor, Michigan.

Kornai, A. (1993). The generative power of feature geometry. Annals of Mathematics and Artificial Intelligence, (8):37-46.

Kuratowski, K. (1930). Sur le problème des courbes gauches en topologie. Fundamenta Mathematicae, 15:271-283.

Misra, V. N. (1966). The Descriptive Technique of Pānini. An Introduction. Mouton \& Co., The Hague, Paris.

Petersen, W. (2004). A mathematical analysis of Pāninini's Śivasūtras. Journal of Logic, Language, and Information, 13(4):471-489.

Petersen, W. (2008). Zur Minimalität von Pānininis Śivasūtras - Eine Untersuchung mit Methoden der Formalen Begriffsanalyse. PhD thesis, University of Düsseldorf.

Petersen, W. (2009). On the construction of Sivasūtras-alphabets. In Kulkarni, A. and Huet, G., editors, Sanskrit Computational Linguistics, volume 5406 of Lecture Notes in Computer Science, pages 78-97, Berlin, Heidelberg. Springer.

Platt, C. R. (1976). Planar lattices and planar graphs. Journal of Combinatorial Theory (B), 21:30-39.

Staal, F. J. (1962). A method of linguistic description. Language, 38:1-10.

Staal, F. J. (1995). The Sanskrit of science. Journal of Indian Philosophy, 23(1):73-127.

Vennemann, T. (1970). The German velar nasal: a case for abstract phonology. Phonetica, 22(65-81). 
Whitney, W. D. (1889). Sanskrit Grammar. Harvard University Press, Cambridge.

Wiese, R. (1996). Phonology of German. Oxford University Press, Oxford. 